\title{
ASSOCIATION OF BODY MASS INDEX WITH INTERARM BLOOD PRESSURE DIFFERENCE: A COMPARATIVE AND CROSS SECTIONAL STUDY
}

\author{
Namala Surya Kumari1, Vikram Venkateswarulu², Reyya Mohan Sundar ${ }^{3}$, Swapna Micheal Bandela ${ }^{4}$,Chadalavada Srinivas ${ }^{5}$ \\ ${ }^{1}$ Assistant Professor, Department of Anatomy, GSL Medical College, Rajahmundry, Andhra Pradesh. \\ 2 Final Year Post Graduate, Department of Physiology, GSL Medical College, Rajahmundry, Andhra Pradesh. \\ ${ }^{3} 2^{\text {nd }}$ year Post Graduate, Department of Physiology, GSL Medical College, Rajahmundry, Andhra Pradesh. \\ ${ }_{4}^{4} 2^{\text {nd }}$ year Post Graduate, Department of Physiology, GSL Medical College, Rajahmundry, Andhra Pradesh. \\ 5 Professor and HOD, Department of Physiology, GSL Medical College, Rajahmundry, Andhra Pradesh.
}

\section{ABSTRACT}

The major health problem faced by the $13 \%$ of world population is obesity and this obesity and overweight may lead to many health consequences such as cardiovascular diseases, diabetes and some cancers to mention a few. Objective of present study is to find the relation between the increased BMI and the interarm blood pressure difference.

\section{MATERIALS AND METHODS}

The present study was conducted on 180 subjects with age ranging from 18 to 50 years. They were divided into two groups based on the BMI. Subjects with normal BMI $\left(<25 \mathrm{Kg} / \mathrm{M}^{2}\right) \mathrm{n}=100$ and subjects $(\mathrm{n}=80)$ with overweight $\left(\mathrm{BMI}>25 \mathrm{Kg} / \mathrm{M}^{2}\right)$. The study was conducted in the GSL Medical College and General Hospital, Rajahmundry.

\section{RESULTS}

On comparing the results in overweight subjects in the age group of 40-50 were found to have interarm difference in the mean systolic blood pressure of more than $10 \mathrm{mmHg}$, i.e. Mean value of $13.04 \pm 2.34(<0.001)$.

\section{CONCLUSION}

The overweight individuals with age more than 40 years, there is interarm difference in the mean systolic blood pressure, which is an indicator of peripheral vascular disease.

\section{KEYWORDS}

BMI, Interarm Blood Pressure Difference.

HOW TO CITE THIS ARTICLE: Kumari NS, Venkateswarulu V, Sundar RM, et al. "Association of body mass index with interarm blood pressure difference: a comparative and cross sectional study." Journal of Evolution of Medical and Dental Sciences 2015; Vol. 4, Issue 103, December 24; Page: 16850-16851, DOI: 10.14260/jemds/2015/2532

\section{INTRODUCTION}

Overweight and obesity are defined as abnormal excessive fat accumulation that may impair health. In 2014, more than 1.9 billion people, 18 years and older were overweight (BMI is equal or greater than $25 \mathrm{Kg} / \mathrm{M}^{2}$ ). Increase in the $\mathrm{BMI}$ is major risk factor for health abnormalities like cardiovascular diseases, musculoskeletal disorders and some form of cancers. ${ }^{1}$ Physical inactivity, unhealthy diet and hypertension are seen in people with overweight and cardiovascular diseases. Recording of blood pressure is one basic investigation that is routinely done by the physician at any health care setup. Various researchers found that there is a difference in the blood pressure readings between the arms in general population.2,3,4 The current guidelines recognized the need to check blood pressure in both arms, but many clinician does not pay much attention to it.2,5,6,7 An interarm difference of less than $10 \mathrm{mmHg}$ is considered as normal and more than $20 \mathrm{mmHg}$ may indicate underlying vascular disease. ${ }^{2}$ As the interarm difference in the blood pressure may be a sign of underlying cardiovascular disease, our aim of present study is

Financial or Other, Competing Interest: None.

Submission 21-11-2015, Peer Review 23-11-2015,

Acceptance 18-12-2015, Published 23-12-2015.

Corresponding Author:

Dr. Srinivas C. $H$,

Professor and HOD,

Department of Physiology,

GSL Medical College,

Rajahmundry, Andhra Pradesh.

E-mail: chadalavadasrinivas@yahoo.com

DOI:10.14260/jemds/2015/2532 to find the relation between the increased BMI on the interarm difference in the blood pressure in various age groups.

\section{MATERIAL AND METHODS}

The present study was conducted in the GSL Medical College and General Hospital, Rajahmundry, Andhra Pradesh. Institutional Ethics Committee's approval was taken prior to the study. The present study includes 100 normal weight individuals whose BMI is less than $25 \mathrm{~kg} / \mathrm{M}^{2}$ and 80 subjects were overweight with BMI between 25 to $30 \mathrm{~kg} / \mathrm{M}^{2}$. We have divided them into two age groups, one group between 18 to 25 years and another group between 40 and 50 years. The inclusion criteria include age as mentioned above and subjects should be nonsmokers, nondiabetic without any known cardiovascular diseases. Subjects between 26-39 years of age, known hypertensive and on any sort of medication were excluded. Informed written consent was taken from all the participants after explaining the procedure in their language. BMI is calculated by formula BMI=Weight/Height. ${ }^{2}$ where weight in kilograms and height in meters is expressed. Subjects with BMI less than $25 \mathrm{~kg} / \mathrm{M}^{2}$ were considered as nonobese healthy individuals and subjects with BMI more than $25 \mathrm{~kg} / \mathrm{M}^{2}$ and less than $30 \mathrm{~kg} / \mathrm{M}^{2}$ were considered as overweight.

The subjects were advised to report at the laboratory of the hospital after a light breakfast without taking any stimulant beverages like coffee or tea. They were made to rest for a few minutes and anthropometric measurements were taken. Height was measured without shoes in meters nearest to $0.1 \mathrm{~cm}$ with wall mounted height measuring scale (ws708) and weight was measured nearest to 0.1 kilograms on a standard weighing machine with minimal clothing. The resting 
pulse rate was taken and the blood pressure was measured using sphygmomanometer in both arms.

\section{STATISTICAL ANALYSIS}

The data obtained was analyzed and expressed as mean and standard deviation. The statistical software namely SAS 9.2, SPSS 15.0 were used for the analysis of the data. For testing the significance of means, the Z-test was done between the two groups and significance was based on $p$ value $(\leq 0.05)$.

\section{RESULTS}

When the results were observed, we found that the interarm difference in the diastolic blood pressure almost negligible. When the mean systolic blood pressure interarm difference $(2.64 \pm 0.33)$ in non-obese individuals of 18 - 25 years age group when compared with overweight subjects of same age group, there is no significant change is seen ( $p$-value $>0.070$ ). There is significant difference in the systolic interarm mean values between non-obese and overweight subjects of 40-50 years age group with a P-value of $<0.001$.

\begin{tabular}{|c|c|c|c|c|c|c|}
\hline \multirow[t]{2}{*}{ Age in Years } & \multicolumn{2}{|c|}{$\begin{array}{c}\text { Non-obese subjects } \\
(\mathrm{N}=50) \\
\text { interarm systolic pressure } \\
\text { difference mmHg }\end{array}$} & \multicolumn{2}{|c|}{$\begin{array}{l}\text { Overweight subjects }(\mathrm{N}=40) \\
\text { interarm systolic pressure difference } \mathrm{mmHg}\end{array}$} & \multirow[t]{2}{*}{ T-value } & \multirow[t]{2}{*}{$P$-value } \\
\hline & Mean & SD & Mean & SD & & \\
\hline 18-25 group & 2.64 & \pm 0.33 & 2.86 & \pm 0.42 & 2.783 & $>0.070$ \\
\hline 40-50 group & 3.22 & \pm 0.61 & 13.04 & \pm 2.34 & 28.52 & $<0.001^{*}$ \\
\hline
\end{tabular}

\section{DISCUSSION}

Blood pressure difference between arms is not uncommon during routine examination in the regular health care setup. But how much difference is present is the matter of concern. The interarm difference of blood pressure was recognized more than 100years ago. ${ }^{8}$ In the present on 180 subjects, we have observed that the interm systolic pressure difference is not significant in the younger age group of 18 to 25 years, who are non-obese and their BMI is less than $25 \mathrm{~kg} / \mathrm{m}^{2}$. We also found that even in overweight younger individuals whose BMI is more than $25 \mathrm{~kg} / \mathrm{m}^{2}$ difference is found. But positive correlation was seen in the individuals between ages of 40-50 years with overweight. Our study is in consistence with study of Balkishan Sharma and Sameer Inamdar. ${ }^{9}$ that there is difference in the systolic blood pressure between the arms, but in our study we did not find any significant difference in the diastolic blood pressure between the arms in any age group.

Various researchers found that there is varying degree of difference in the interarm blood pressure. In one randomized investigation on which arm to check first, in an attempt to determine if there was a relaxation effect and results were insignificant and authors said that "age was the only significant predictor of clinically significant variation in inter-arm blood pressures. ${ }^{10,11}$ As stated by some researchers, this interarm difference in the blood pressure may be due to the underlying congenital conditions like aortic coarctation and thinning of one of the subclavian, axillary or brachial arteries or may be due to acquired conditions like aortic dissections, atheromas, thrombus, embolus or any mass in the chest cavity that is causing compression of the main arteries. ${ }^{10}$ The interarm difference in the systolic pressure in younger individuals may occur due to simple compression of artery by a muscle or any solid structure, which prevents smooth flow of blood. But in the elderly people it may arise from atherosclerosis or artery clogging diseases, which may later lead to more dreaded complications such as myocardial infarctions, strokes and peripheral artery diseases. ${ }^{12}$

There were certain limitations to this study, as the study was conducted based on the BMI as indicator obesity, but calculating the body fat percentage and influences of gender on these parameters may give more reliable results. In conclusion, the overweight individuals over 40years of age showed variation in the systolic blood pressure between the arms.

\section{REFERENCES}

1. World health organization. Obesity and overweight fact sheet.http://www.who.int/medicentre/

factsheet/fs311/en/.

2. Christopher EC, Rod ST, Angela CS, et al. The difference in the blood pressure readings between arms and survival: primary care cohort study. BMJ 2012; 344:e1327.

3. Ho-ming S, et al. Association of interarm systolic blood pressure difference with atherosclerosis and left ventricular hypertrophy. PloS ONE (2012);7(8):e41173.

4. Clark CE, Campbell JL, Evans PH, et al. Prevalence and clinical implications of the interarm blood pressure difference: a systematic review. Journal of human hypertension 2006;20:923-931.

5. Williams B, Poulter NR, Brown MJ, Davis M, McInnes GT, Potter JF, et al. Guidelines for management of hypertension: report of the fourth working party of the British Hypertension Society, 2004-BHS IV. J Hum Hypertens 2004;18:139-85.

6. Mancia G, De Backer G, Dominiczak A, Cifkova R, Fagard $\mathrm{R}$, Germano G, et al. Guidelines for the management of arterial hypertension: the task force for the management of arterial hypertension of the European Society of Hypertension (ESH) and of the European Society of Cardiology (ESC). Eur Heart J 2007;28:1462-536.

7. Heneghan C, Perera R, Mant D, et al. Hypertension guideline recommendations in general practice: awareness, agreement, adoption and adherence. Br J Gen Pract 2007;57:948-52.

8. Cyriax EF. Unilateral alteration in blood-pressure caused by unilateral pathological conditions: the differential blood pressure sign. QJ Med 13:143-164.

9. Balkishan S, Sameer I. The assessment of the clinical significance of interarm blood pressure difference and depression in general practice: A health initiative crosssectional study. Journal of health science 2013;3(4):303-316.

10. Bruce MG. Wide blood pressure variation between arms. Medscape 20.2002.

11. Pesola GR, Pesola HR, Lin M, et al. The normal difference in difference in bilateral indirect blood pressure recordings in hypertensive individuals. Acad Emerg Med 2002;9:342-345.

12. Patric JS. Different blood pressure in right and left arms could signal trouble.

http://www.health.harvard.edu/blog/-201202014174. 